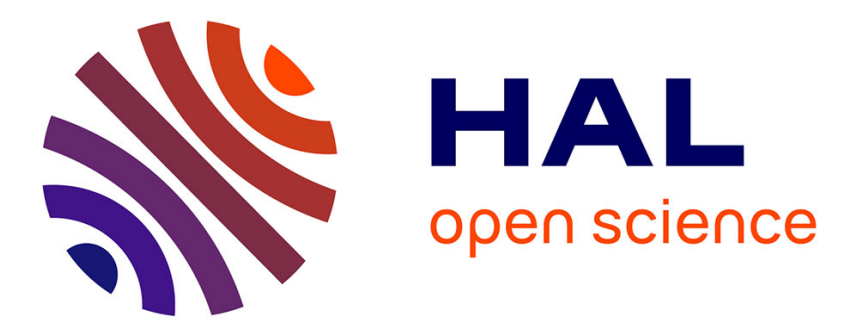

\title{
Precision and surface integrity of threads obtained by form tapping
}

Guillaume Fromentin, Gérard Poulachon, Alphonse Moisan, Benoit Julien, J.

Giessler

\section{- To cite this version:}

Guillaume Fromentin, Gérard Poulachon, Alphonse Moisan, Benoit Julien, J. Giessler. Precision and surface integrity of threads obtained by form tapping. CIRP Annals - Manufacturing Technology, 2006, 541 (1), pp.519-522. hal-01133716

\section{HAL Id: hal-01133716 https://hal.science/hal-01133716}

Submitted on 1 Apr 2015

HAL is a multi-disciplinary open access archive for the deposit and dissemination of scientific research documents, whether they are published or not. The documents may come from teaching and research institutions in France or abroad, or from public or private research centers.
L'archive ouverte pluridisciplinaire HAL, est destinée au dépôt et à la diffusion de documents scientifiques de niveau recherche, publiés ou non, émanant des établissements d'enseignement et de recherche français ou étrangers, des laboratoires publics ou privés. 


\title{
Precision and surface integrity of threads obtained by form tapping
}

\author{
G. Fromentin ${ }^{1}$, G. Poulachon ${ }^{1}$ (2), A. Moisan ${ }^{1}$ (1), B. Julien², J. Giessler ${ }^{3}$ \\ ${ }^{1}$ LaBoMaP, Dept. of Machining, ENSAM, Cluny, France \\ ${ }^{2}$ PSA Peugeot Citroën (3), La Garenne Colombe, France \\ ${ }^{3}$ Prototyp Werke Zell, Zell am Hamersbach, Germany
}

\begin{abstract}
Largely applied to internal threading of extruded tubes, cold form tapping is now becoming a promising process for internal threading of holes in non ferrous and ferrous solid components, more particularly for mass production in the automotive industry. The aim of this study is to present the surface properties of the threads resulting from form tapping. Geometrical characterization, surface texture, mechanical and metallurgical observations are investigated. The results obtained are discussed according to the input parameters of the process, and are compared to those obtained from cut tapping. The strength of the work material and the influence of the lubricant are the two main parameters affecting the process, and a correlation with the tapping torque is proposed. Finally, the characteristics of the thread surface depend on the parameters of the tapping operation, thus it has to be taken into account in the design approach when this tapping process is chosen.
\end{abstract}

\section{Keywords:}

Cold form tapping, Surface properties, Assembly

\section{INTRODUCTION}

The threaded joint is one of the most widely used solutions for assembling mechanical parts, because it leads to an assembly having a high strength and high rigidity. Moreover the use of thread allows disassembly for maintenance and recycling. Concerning the manufacturing of internal threads or nuts, two main processes are available: cut tapping and form tapping. The choice of one of these processes has to result from considerations including process aspects, and also from an analysis of the specifications and characteristics of the internal thread.

Form tapping is a different process from cut tapping for obtaining internal thread. Cut tapping is a machining process, the thread results from chip removal. In the case of form tapping, the thread is formed only by the displacement of the work material.

A new growth of interest in this technique is obvious in the metal forming industry, and in particular in the automotive industry, due to the advantages inherent to the process itself: a higher number of tapped holes during the tool life, minimum quantity of lubricant, better reliability, better cleanliness (no chips).

The thread obtained by form tapping is characterized by the appearance of a split crest at the top of the thread, as shown in Figure 1. Its rate of formation, as it was shown by S. Agapiou [1], depends on the hole diameter before tapping. The smaller the hole diameter is, the smaller will be the split crest at the top of the thread after the form tapping operation. This forming process is available both with high ductile alloys such as non ferrous metals [1-4], and also with hardened steels as shown by $[5,6]$. Analytical models of this forming process have been proposed by $\mathrm{S}$. Chowdhary [3] and by W.E. Henderer [7].

So far, only a few studies have been carried out on form tapping, and most of them deal mainly with process aspects, without linking characterization of the formed thread. It is probably because the technical specifications for tapped holes are coming from characteristics of cut threads.

The present study deals with the characterization of the internal thread obtained by the form tapping as a function of two process parameters: the lubricant, and the holder.
Different properties are analyzed: geometrical precision, metallurgical aspects, and mechanical properties. A comparison with cut tapping is conducted.

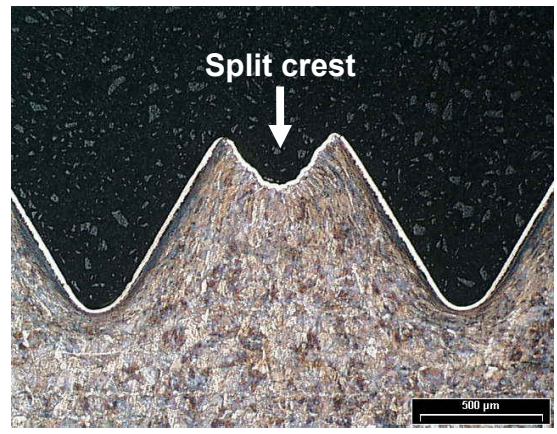

Figure 1: M12×1.5 formed thread in C70 steel.

Tests are conducted with a DMC65V 3 axis machining centre equipped with a vertical spindle controlled both in speed and in position. Blind holes are tapped either with a rigid or with a floating holder. The taps used are M12×1.5 $6 \mathrm{HX}$ cut tap or thread former, made of sintered HSSE and TiN coated. Their design is composed of 3 flutes for the cutting tool, and 5 lobes on the forming tool. They have a short entry taper with 3 pitches. Two different fluids are used for tapping. The first fluid is an oil containing additives based on sodium sulfonates. The second is a $5 \%$ water based emulsion. The work material used is a $\mathrm{C} 70$ carbon steel. It has a ferrito-perlitic structure and its ultimate strength is $900 \mathrm{MPa}$.

\section{GEOMETRICAL CHARACTERIZATION}

Geometric precision is one of the most important characteristics of the thread to guarantee a functional assembly. Two properties are analyzed: pitch error and flank straightness. Threads are measured with a mechanical stylus having a radius equal to $25 \mu \mathrm{m}$ and using a 3D surface measuring instrument.

\subsection{Thread pitch deviation}

On first sight, the thread quality depends mainly on tap runout during machining, which leads to a pitch error. When a rigid holder is used, the occurrence of a 
synchronous error, between the linear motion and the rotation linked by the tap pitch, leads to an increasing of thrust force on the tap and on the workpiece. But, if a floating holder is used, the synchronous error is absorbed by a compression of the holder spring having a very low stiffness compared to the previous holder, and a lower force is transmitted to the tool as shown on Figure 2.

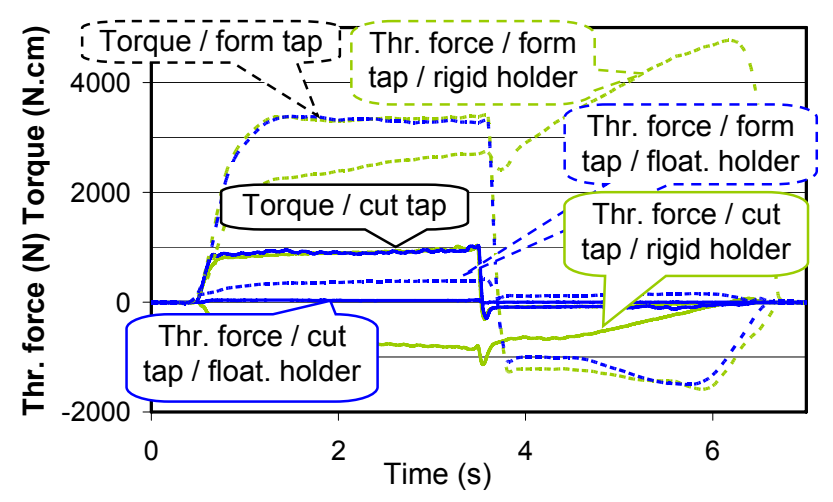

Figure 2: Thrust force and torque during tapping.

Figure 3 shows the pitch error along the thread. The worst pitch is always the first one, whether the thread is obtained by cutting or forming. There is inevitably an error on the feed control of the tool during the entrance in the workpiece. The cut tap makes pitches which are too large (the error is positive), because it has right spiral flutes, then the axial force on the tool is in the feed direction, and the tap runs out. In the case of form tapping, the axial force is in the opposite direction, and the tool does not make too large pitches.

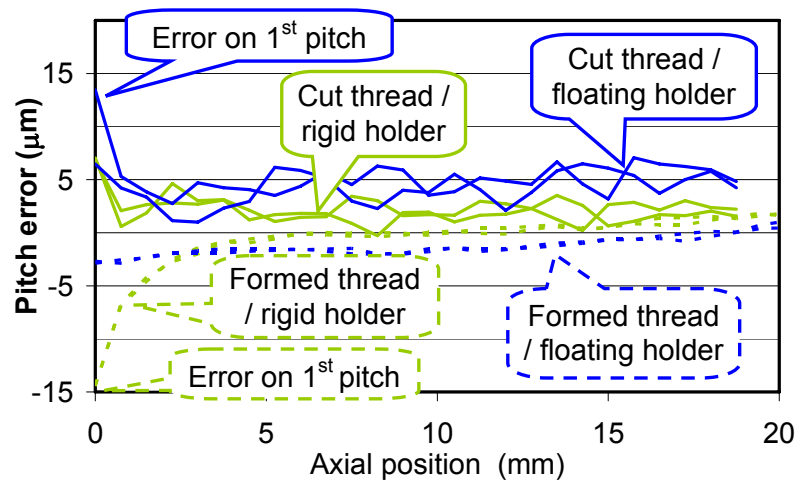

Figure 3: Pitch error of cut and form thread.

The use of a rigid holder decreases the cutting tap runout, thus reducing the pitch error by half. But in the case of form tapping, this holder can bring about an error on the first pitches due to significant forces caused by the tool entrance in the workpiece. Except for this point, the use of form tapping leads to a lower and constant error on the thread pitch compared to the case of cut tapping.

\subsection{Flank straightness}

Another geometric property needed for a tapped thread is the straightness of its flanks to assure the contact with the screw. From the scanned thread profile used for the measurements of the pitch deviation, each flank is identified and the straightness is calculated after considering a least square line as shown in Figure 4.

Figure 5 shows the flank straightness of cut and formed threads. Cut threads also have a lower quality regarding the straightness criteria. The first pitch is again the worst because of tool feed control during entrance, as already explained, and the use of a rigid holder contributes to reduce this error. The flank straightness deviation of formed thread is between $1 \mu \mathrm{m}$ and $4 \mu \mathrm{m}$, which shows the accuracy of threads obtained by forming. The flank straightness deviation of those tapping by cutting, it is alternatively around $5 \mu \mathrm{m}$ and $20 \mu \mathrm{m}$. The flanks having the worst straightness are those oriented toward the bottom of the hole. This can be explained by the pulling force on the holder after spindle reversing and when the cutting tap goes out of the workpiece. Thus, the cutting edges of the tool are in contact with these flanks and may damage them during the back travel of the tool. In the case of form tapping the tool does not have any cutting edge and there is only friction between it and the thread during the back travel. Consequently, the type of holder does not influence the flank straightness of threads produced by form tapping.

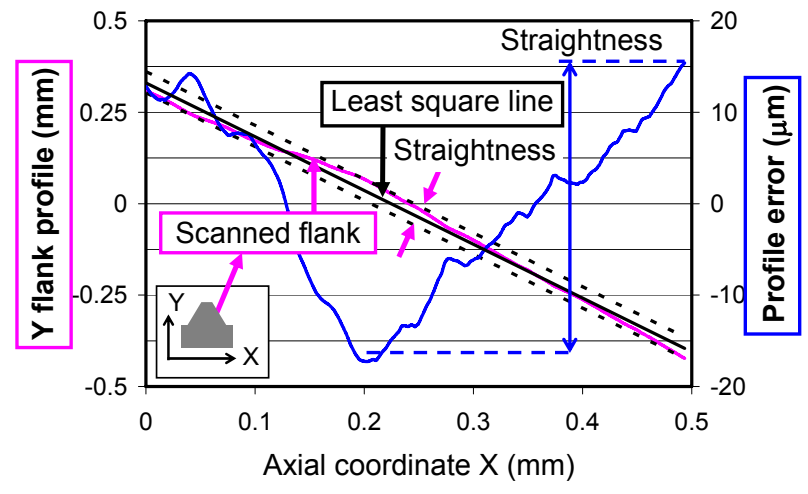

Figure 4: Flank straightness of a cut thread.

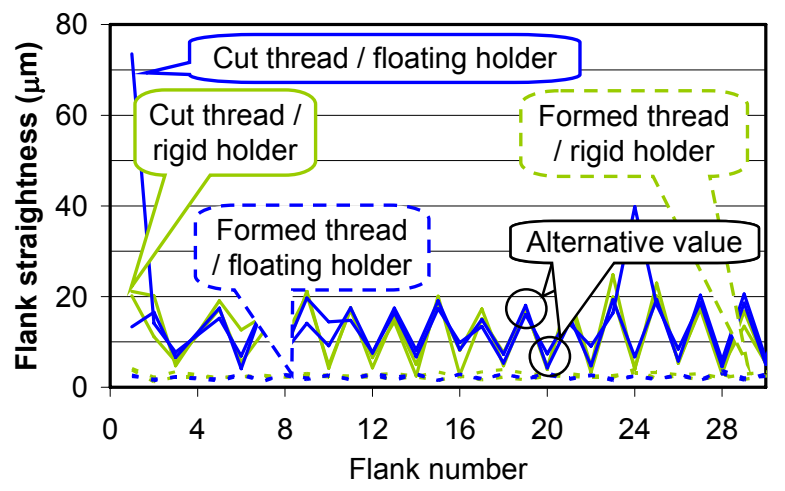

Figure 5: Flank Straightness of cut and formed thread.

\section{SURFACE INTEGRITY IN FORM TAPPING}

\subsection{Strain hardening on thread}

The use of form tapping leads to plastic flow of the work material when making the thread. No metallurgical transformation is observed, nevertheless this process necessarily involves a strain hardening of the material constituting the thread. This strain hardening is quantifiable by microhardness measurements.

Figure 6 shows measurement profiles at the root of the thread which appears to be the most deformed zone inside the thread. The initial hardness of the work material is $285 \mathrm{HV}$, and the hardness at $15 \mu \mathrm{m}$ from the root is around $540 \mathrm{HV}$ when the emulsion is used for tapping. In this case it represents an increase of $90 \%$ in hardness. Moreover, the hardness measured directly on the flank of this thread is $770 \pm 30 \mathrm{HV}$. This value is comparable to the hardness of the HSSE substrate of the form tap, which involves that the coating on the tool is essential for form tapping high strength steel. By using the oil, which is a much better lubricant compared to the coolant according to a lower tapping torque $(26.3 \mathrm{~N} . \mathrm{m}$ against $41.7 \mathrm{~N} . \mathrm{m})$, the strain hardening appears also to be considerably reduced as shown Figure 6. 


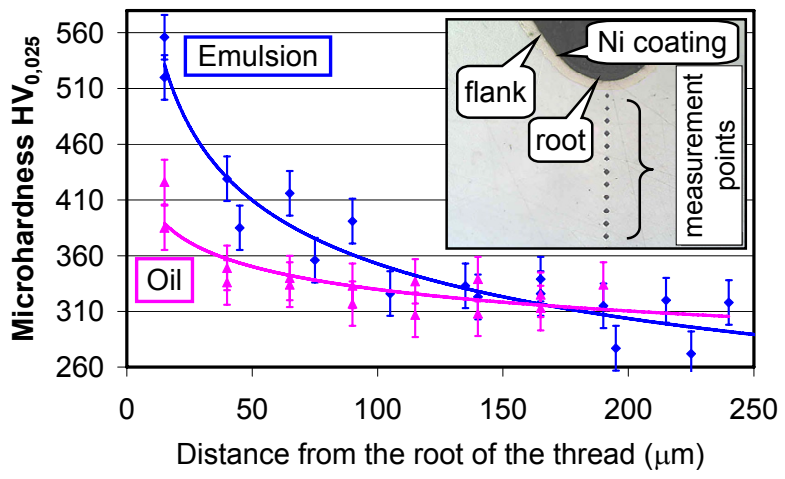

Figure 6: Strain hardening at the root of formed thread.

These hardness measurements show that the thread obtained by form tapping undergoes a high strain hardening and there is a strongly deformed layer at the thread surface. This deformed layer is largely influenced by the intensity of the friction between the thread former and the work material. As a consequence, the lubricant has a prime importance on thread characteristics. The strain hardening would raise the strength of the thread. The drawback is that this hardening has necessarily an effect on wear of the form tap, which would be considerably reduced by using an efficient lubricant.

\subsection{Residual stresses and metallurgical texture on the thread flank}

First of all, using a SetX device, residual stress measurements by $X$ ray diffraction are conducted on the flank which is the largest area of the thread. The $\{211\}$ planes of the ferritic phase are used for the diffraction. Despite a long time of exposure, the intensity of diffraction peaks is not sufficient to measure residual stresses with a good accuracy, the area of the diffracted surface being too small. The results on the flank of the thread tapped with the oil are shown in Table 1.

\begin{tabular}{|c|c|c|}
\hline Stress & Measured value & Uncertainty \\
\hline$\sigma_{\mathrm{rr}}$ & $-549 \mathrm{MPa}$ & $\pm 168 \mathrm{MPa}$ \\
\hline$\sigma_{\mathrm{r} \theta}$ & $39 \mathrm{MPa}$ & $\pm 29 \mathrm{MPa}$ \\
\hline$\sigma_{\theta \theta}$ & $-283 \mathrm{MPa}$ & $\pm 162 \mathrm{MPa}$ \\
\hline
\end{tabular}

Table 1: Residual stress on the flank of the thread tapped with oil (r: radial direction / $\theta$ : tangential direction).

Despite poor precision, it shows that the residual stresses in the radial and tangential direction, $\sigma_{\mathrm{rr}}$ and $\sigma_{\theta \theta}$, are compressive stresses which would be favourable to fatigue life of the thread. Concerning the shear stress, $\sigma_{\mathrm{r} \theta}$, it is zero, and it would be linked to the efficiency of the oil used.

In order to identify the material texture, Electron Back Scattered Diffraction (EBSD) technique is used rather than $X$ ray diffraction which needs a larger surface and limits the incidence angle during analysis. The surface analyzed needs to be prepared by mechanical-polishing and electrochemical-polishing. As a consequence, it is the subsurface which is measured and not exactly the surface itself, on which residual stresses are measured. Figure 7 shows the $\{100\}$ pole figures on the raw material, i.e. before tapping, and on the flank of the thread tapped with oil. Initially, the work material is little textured; the intensity does not increase over 3 . Three poles at $90^{\circ}$ can be seen on Figure $7(\mathrm{a})$, meaning there is only one texture. This texture is probably linked to the hot rolling and recrystallization of the raw material. After tapping, Figure 7(b) shows that the material is quasi isotropic. In conclusion, form tapping of a ferrito-perlitic steel induces compressive stress and the plastic flow tends to reduce initial texture of the work material.

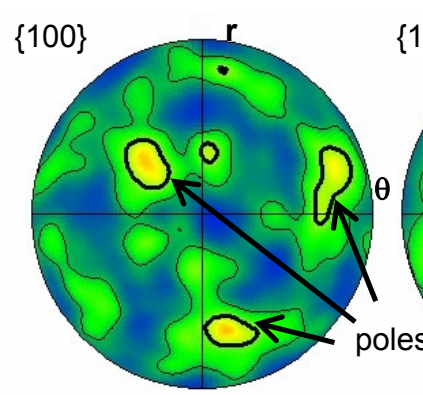

Raw material texture (a)

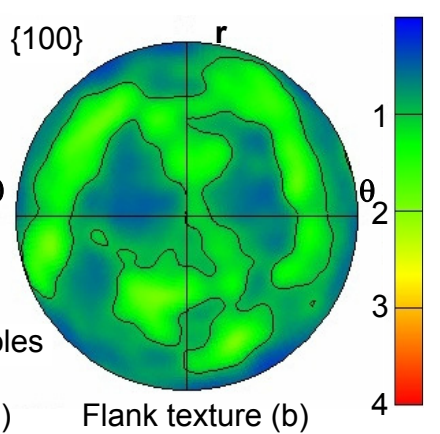

Flank texture (b)
Figure 7: $\{100\}$ Pole figures measured by EBSD.

\section{MECHANICAL ASPECTS}

Several considerations may concern the mechanical properties of threads. In this study, only two characteristics are investigated: the friction between the threaded holes and screws, and the ultimate strength of the tapped threads.

\subsection{Friction}

The friction coefficient between the flanks of the internal and the external thread needs to be known in order to determine the tightening torque to guarantee a functional assembly. If the friction coefficient between the threaded surfaces is overestimated, then the tensile force inside the screw will be too high. As a consequence, the screw may break, or the threaded hole may be damaged or both. On the opposite, if the friction coefficient is underestimated, the tensile force will be too low, and then it will not guarantee the assembly.

A special device has been designed in order to measure directly the tightening torque without being influenced by the friction under the screw head. Dry friction conditions are obtained by cleaning threads with solvent and using ultrasonic chatter. No agent is used to lubricate the threads during tightening. Several threaded holes having different characteristics are tested.

After tapping, sulphur coming from oil is measurable on the flank surfaces of the formed thread by EDS analysis (Electro Dispersive Spectrum). This occurrence of sulphur characterizes a tribological layer caused by the chemical reaction between the oil additives and the worked steel. This tribological layer leads to reduced friction during tapping. There is no layer on a formed thread with emulsion, which explains the lack of lubricating action of this fluid characterized by a higher torque during tapping and a higher strain hardening (cf. $\S 3.1$ ). Cut threads are machined with the same oil that is used for obtaining formed threads. Nevertheless, there is also no tribological layer on the flank surfaces of these cut threads, showing a different lubricating action of the oil than in form tapping.

Figure 8 summarizes results of tightening tests. Despite these differences on the flank surfaces, it is difficult to identify a significant effect on the value of the friction coefficient. The measurement dispersions are too large compared to the difference between the three types of threads. The dispersion is particularly important for threads formed with oil. The friction coefficient may be included in a range from 0.2 to 0.43 . Thus, the friction coefficient may be lower or higher than in the case of a cut thread which has the worst flank straightness. These results are also influenced by the variation of characteristics of the screws used for the tightening tests. No attention has been paid to them except their geometrical quality class which is the same than those of the threaded holes: $6 \mathrm{~h}$. Screws are produced in mass production by rolling process, and there is chance of damage due to impact. 


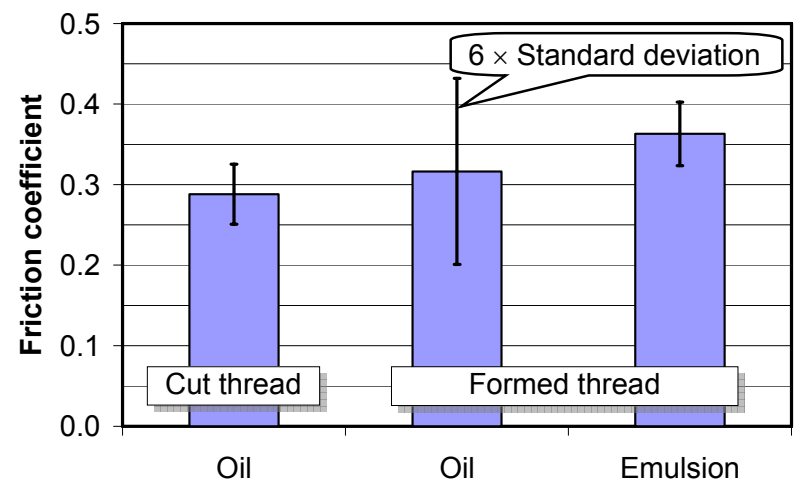

Figure 8: Friction coefficient between internal and external threads.

From an industrial point of view, when there are many variations on the machining process, on the screws, and on the tightening process, the conclusion is that formed threads have to be considered as being identical to cut threads relatively to the tightening torque.

\subsection{Thread strength}

The basic property of thread holes is their strength. Quasi static tensile tests are conducted to quantify and to compare the characteristics of threads obtained by cut tapping and by form tapping. For this goal, fracture of the internal thread has to be realized without the failure of the screw. Such comparison tests may not be done with the C70 carbon steel used for all the previous characterizations. It has an ultimate stress equal to $900 \mathrm{MPa}$ and with high strength screws $(1080 \mathrm{MPa})$, the screw will also be damaged during tensile tests. Consequently, threaded holes are produced in a C22 low carbon steel (540 MPa) for making these characterizations. The strength of the tapped hole material being half the strength of the screw, the fracture of the internal thread will be caused without external thread damage, according to the analytical predictive model of E.M. Alexender [8].

The thread length between tapped hole and screw is fixed to $3 \mathrm{~mm}$, i.e., two pitches, for the breakage tests. Figure 9 shows the ductile rupture features obtained in the case of a C22 cut thread.

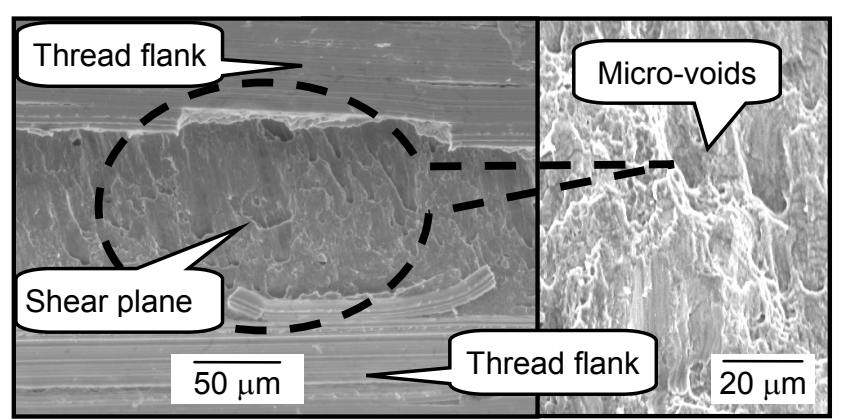

Figure 9: SEM picture of fracture pattern on cut thread.

Figure 10 sums up the results of tensile tests. Despite the split crest, the strength increases by $27 \%$ by using the form tapping process in $\mathrm{C} 22$ steel. The uniform shear stress increases from $270 \mathrm{MPa}$ to $380 \mathrm{MPa}$. This gain is attributed to the strain hardening induced inside the thread during form tapping (cf. §3.1). The value of the maximum tensile force given by the Alexander model is between those measured with the cut and the form thread. With C70 threads, an increase of strength can not be characterized with $1080 \mathrm{MPa}$ screws. Thus, form tapping is not motivated by increasing strength of this assembly, but it would be by other properties of the process, or of the threads produced.

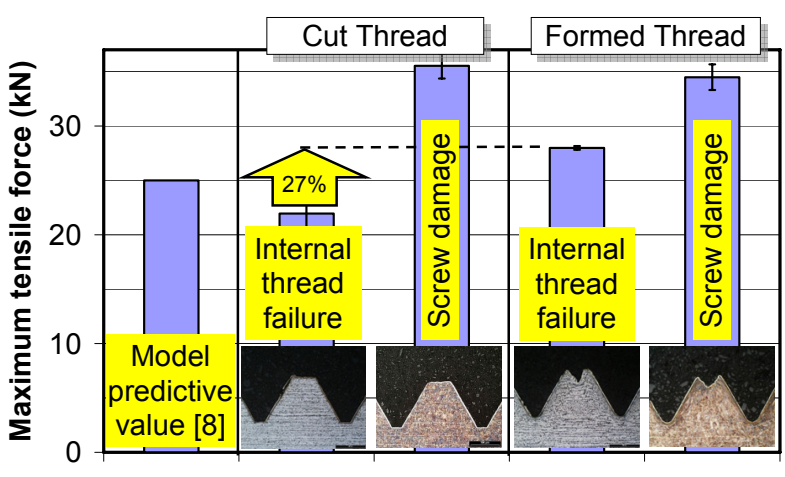

C22 steel C22 steel C70 steel C22 steel C70 steel

Figure 10: Thread strength under tensile force.

\section{CONCLUSION}

The major property of formed threads, in the case of steels, is the high strain hardening, which results from the plastic flow under very severe friction conditions at the interface with the tap, and leads to a strongly deformed layer at the thread surface. The lubricating effect of the tapping fluid is a preponderant operational parameter. It considerably influences the increase in hardness and in thickness in the deformed layer and it also influences on the tool damage and wear. Nevertheless, the strain hardening is responsible for an increase in formed thread strength under static force, compared to those obtained by cut tapping. Residual stresses in the deformed layer are compressive due to the predominance of their mechanical origin, which would increase fatigue strength.

The second dominant property of formed threads is the geometrical quality which is much better compared to those obtained by cutting. Moreover, the tightening torque is unchanged by using form tapping, which facilitates the change of the cut tapping to the form tapping.

Form tapping performance has been established on process aspects as well as on thread characteristics, and this process would be an alternative to cut tapping.

\section{REFERENCES}

[1] Agapiou, J.S., 1994, Evaluation of the effect of high speed machining on tapping, Journal of Manufacturing Science \& Engineering Technology, ASME, 116:457462.

[2] Ivanov, V., Kirov, V., 1996, Rolling of internal threads: Part 1, Journal of Materials Processing Technology, 72:214-220.

[3] Chowdhary, S., Kapoor, S.G., DeVor, R.E., 2003, Modeling forces including elastic recovery for internal thread forming, Journal of Manufacturing Science \& Engineering, ASME, 125:681-688.

[4] Chandra, R., Das, S.C., 1975, Forming taps and their influence on production, Journal of India Engineering, 55:244-249.

[5] Fromentin, G., Poulachon, G., Moisan, A., 2002, Thread forming tapping of alloyed steel, ICME Proceedings, Naples, Italy, 115-118.

[6] Fromentin, G., Poulachon, G., Moisan, A., 2002, Metallurgical aspects in cold forming tapping, NCMR Proceedings, Leeds, UK, 373-377.

[7] Henderer, W.E., B.F. von Turkovich, 1974, Theory of the cold forming tap, Annals of the CIRP, 23:51-52.

[8] Alexander, E.M., 1977, Analysis and design of threaded assemblies, International Automotive Engineering Congress and Exposition, Detroit, USA. 